University of St. Thomas, Minnesota

UST Research Online

Operations and Supply Chain Management

Faculty Publications

Operations and Supply Chain Management

2013

Evaluating Product-Centric Continuous Improvements: Impact on Competitive Capabilities and Business Performance

Debasish N. Mallick

University of St.Thomas, Minnesota, dnmallick@stthomas.edu

Larry P. Ritzman

Boston College, ritzman@bc.edu

Kingshuk K. Sinha

University of Minnesota - Twin Cities, ksinha@umn.edu

Follow this and additional works at: https://ir.stthomas.edu/ocbopmtpub

Part of the Business Administration, Management, and Operations Commons, Management Sciences and Quantitative Methods Commons, and the Operations and Supply Chain Management Commons

This Article is brought to you for free and open access by the Operations and Supply Chain Management at UST Research Online. It has been accepted for inclusion in Operations and Supply Chain Management Faculty Publications by an authorized administrator of UST Research Online. For more information, please contact asle4660@stthomas.edu. 


\title{
Evaluating Product-Centric Continuous Improvements: Impact on Competitive Capabilities and Business Performance*
}

\author{
Debasish N. Mallick, Larry P. Ritzman, and Kingshuk K. Sinha
}

Product-centric continuous improvements (CIs) are actions via which firms modify the design of a product after the start of its production and release into the market. Product-centric CIs are initiated to help build competitive capabilities and sustain competitive advantage throughout the product life cycle. This study complements the perspective pervasive in the extant literature that actions related to product-centric CIs can be disruptive to firms and be associated with negative performance consequences. It investigates a topic that is relatively much less researched, namely the upside potential of product-centric CIs. The empirical analysis is based on data collected from 144 plants in the United States representing process and discrete part manufacturing industries. Specifically, the study analyzes the impact of product-centric CIs on competitive capabilities and business performance. The results of the empirical analysis indicate the following: First, there exist two categories of product-centric CIs: (1) actions for quality improvement and (2) actions for cost reduction. Second, while there is a positive association between each type of CI and the intended competitive capability, there also is a trade-off_i.e., actions for quality improvement increase quality capability but reduce cost capability, and vice versa. Third, there is a strong linkage between business performance and quality capability, but not cost capability. All in all, the study presents empirical evidence that product-centric CIs have a significant impact on competitive capabilities related to quality and cost, and, in turn, have an impact on business performance. From the standpoint of practice, the study suggests that product-centric CIs should be managed to develop competitive capabilities and improve business performance.

\section{Introduction}

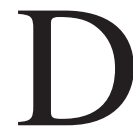
eveloping products that delight customers and create competitive advantage is a major challenge, so is sustaining that advantage after the product release. In practice, product-centric continuous improvements (CIs) are actions via which firms modify the design of a product after the start of its production and release into the market. Product-centric CIs are intended to help build competitive capabilities and sustain competitive advantage throughout the life cycle of a product. Informed by technical and market experience, productcentric CIs can have significant payoffs.

Notwithstanding the upside potential of productcentric CI actions, there are direct and indirect costs of such actions that can be significant. For example, it is not unusual for firms to allocate between $20 \%$ and $50 \%$ of

Address correspondence to: Debasish N. Mallick, Department of Operations and Supply Chain Management, Opus College of Business, University of St. Thomas, Minneapolis, MN 55403, USA. E-mail: dnmallick@ stthomas.edu. Tel: 651-962-4144.

* The authors gratefully acknowledge the insightful comments and constructive suggestions of an anonymous reviewer and the editor on earlier versions of the paper. All errors and omissions are the responsibility of the authors. available engineering capacity to executing improvements related to existing products (Soderberg, Coyne, and Ferguson, 1989; Wheelwright and Clark, 1992). Moreover, in a plant producing a high-technology, electromechanical device, most product-centric CIs were found to be manufacturing related and accounted for $5-6 \%$ of total indirect labor cost (Saeed, Bowen, and Sohoni, 1993). A review of the literature indicates that initiating a product-centric $\mathrm{CI}$ in the shop floor can result in severe disruptions to manufacturing operations that can persist for up to a year (Bohn and Terwiesch, 1999; Hayes and Clark, 1985a, 1985b; Terwiesch and Bohn, 2000). The review of the literature also suggests that the upside potential of product-centric CIs has received much less attention in the literature. The present study is an attempt to address this gap in the literature.

It is well known that new product development is a process of innovation consisting of experimentation and reflection, and is a source of learning and organizational effectiveness (Akgun, Byrne, Lynn, and Keskin, 2007; Leonard-Barton, 1996; Thomke, 1998). Product-centric CIs is a continuation of the innovation process, typically involving experimentation, learning, and creation of new knowledge or combining new with old knowledge after the start of production of a product and its release into the 
market (Almeida, Phene, and Grant, 2003; Carlile and Rebentisch, 2003). This study draws on two phenomena related to organizational learning, namely quality learning curve (Levin, 2000; Schneiderman, 1988; Sterman, Repenning, and Kofman, 1997) and manufacturing learning curve (Alchian, 1959; Levy, 1965; Wright, 1936), to guide our investigation into the impact of product-centric CIs. The hypotheses we develop and test in this study seek to answer the question: How do product-centric CIs

\footnotetext{
BIOGRAPHICAL SKETCHES

Dr. Debasish N. Mallick is an associate professor of technology and operations management at Opus College of Business, University of St. Thomas. Previously, he has worked in manufacturing and service sectors in the United States and abroad, and taught at Virginia Commonwealth University, Boston College, and University of Minnesota. He received his B. Tech. (Honors) in mechanical engineering from the Indian Institute of Technology, M.B.A. from the University of Arkansas, and Ph.D. in Management from University of Texas at Austin. His research interests are in new product development and technology management. His research has appeared in several academic journals including Journal of Operations Management, Production and Operations Management, IEEE Transactions on Engineering Management, Journal of Engineering and Technology Management, Design Management Journal, European Journal of Operational Research, European Journal of Innovation Management, and Journal of Product Innovation Management.
}

Dr. Larry P. Ritzman was the first Thomas J. Galligan, Jr. Professor in operations and strategic management at Boston College and is a professor emeritus from both The Ohio State University and Boston College. He continues writing textbooks, having just finished with his coauthors the 10th edition of Operations Management: Processes and Supply Chains. He received his doctorate at Michigan State University and had prior industrial experience at the Babcock and Wilcox Company. His publications have appeared in such journals as Computers and Operations Research, Decision Sciences, European Journal of Operational Research, Interfaces, Journal of Behavioral Decision Making, Journal of Operations Management, International Journal of Operations and Production Management, International Journal of Production Research, Journal of Operational Research Society, Harvard Business Review, Management Science, Managerial and Decision Economics, $O M E G A$, and Operations Research. He was coeditor of Disaggregation: Problems in Manufacturing and Service Organization. He is a past president and fellow of the Decision Sciences Institute.

Dr. Kingshuk K. Sinha is a professor in the Supply Chain and Operations Department and holder of the Mosaic Company Professorship in Corporate Responsibility at the Carlson School of Management, University of Minnesota. His areas of research interests are: management of technology and innovation, global supply chain management, quality management, and health care supply chain management. His inquiries are predominantly empirical. Typically, he conducts his scholarly projects in collaboration with industry partners. The empirical settings of his projects have included the high tech; health care/medical; retail; food; and energy/oil and gas industries. His papers have appeared in academic journals such as Management Science, Academy of Management Journal, Organization Science, Manufacturing \& Service Operations Management, Information Systems Research, Journal of Accounting Research, Journal of Operations Management, Production and Operations Management, Decision Sciences, and Journal of Service Research. impact a firm's competitive capabilities and business performance?

The remainder of the paper is organized as follows. The next section presents a brief review of the relevant literature. In the following section, the conceptual foundation of the study is presented. Next we present discussion on the data collection, measurement, and research methods used to test the proposed hypotheses followed by a discussion of the results of the empirical analysis. The last section summarizes the contributions of the study, its limitations, and conclusions.

\section{Literature Review}

The literature on product-centric CIs after the start of production of a product and its release into the market has emerged from the manufacturing engineering and production management disciplines. Several early papers have recognized that not all product-centric CIs are alike and suggest a variety of classification schemes (Barzizza, Caridi, and Cigolini, 2001; Diprima, 1982; Reidelbach, 1991) or different kinds of normative approaches for managing them (Chen, Shir, and Shen, 2002; Huang and Mak, 1999; Huang, Yee, and Mak, 2001; Loch and Terwiesch, 1999; Pikosz and Malmqvist, 1998; Saeed et al., 1993; Schmenner and Lackey, 1994; Tavcar and Duhovnik, 2005; Terwiesch and Loch, 1999; Watts, 1984). Several studies have examined scheduling problems within a material requirements planning (MRP) environment using analytical models and simulation techniques (Chalmet, De Bodt, and Van Wassenhove 1985; Ho, 1994; Mather, 1977). They have investigated the link between product-centric CI frequency and scheduling instability, and the impact of lot sizing rules on parts obsolescence. Hayes and Clark (1985a, p. 180) instead have identified the positive side of product-centric CIs, proposing that product-centric CIs would reduce TFP (total factor productivity) in the short run, but increase TFP in the long run. However, data from 12 plants that served as the empirical setting of Hayes and Clark's (1985a) study did not support the long-term gain in TFP as hypothesized, but did show a reduced TFP that lasted up to a year. An ex post analysis of the data led them to recommend that product-centric CIs should be avoided by designing a product right the first time. Specifically, they concluded that (1) the frequency of product-centric CIs may actually improve a plant's tolerance to changes, and (2) minor product-centric CIs had the greatest negative effect while major product-centric CIs actually had a positive effect. Adler and Clark (1991) used data from two manufacturing divisions to recognize the difference 
between "first-order learning" and "second-order learning." Cumulative output volume is used as a measure of first-order experience-based learning and cumulative number of engineering change hours as a measure of the second-order knowledge-based learning. They concluded that product-centric CIs can either impede or enhance production efficiency. Balakrishnan and Chakravarty (1996), on the other hand, captured the trade-off between marketing opportunity and manufacturing costs associated with product-centric CIs in an optimization model. Their results indicated that the enhanced product with increased marketing opportunities may not immediately replace the old product and that the phase-out period of the old product should be chosen to avoid substantial reduction in overall profit. Wanstorm and Johnson (2006) used empirical data from a case study of a supply chain to conclude that product-centric CIs can have both positive and negative effects, as well as direct and indirect effects on the material scrap, administrative, and transport/ handling costs. They also found that a variety of productcentric CI related situations exist within the same company, requiring different planning strategies. Subsequently, they presented a model to manage resources in engineering change situations (Wanstorm, Lind, and Wintertidth, 2006).

Summing up, the literature review indicates that product-centric CIs are inevitable, and their effects ripple throughout the business. Yet, their impact on competitiveness and business performance is not well understood. The limited body of research that does exist on this topic is mostly conceptual, case based, and analytical in nature, but very little by way of empirical research. Conclusions remain incomplete and even sometimes contradictory. The handful of empirical studies on product-centric CIs are based on small sample sizes. A product-centric CI is predominantly seen as a problem rather than an opportunity (Wright, 1998). However, we believe that a better understanding of the relationships among product-centric CIs, competitive capabilities, and business performance is a precursor to more effective management of the CI process (Adler and Clark, 1991; Balakrishnan and Chakravarty, 1996; Hayes and Clark, 1985a, 1985b).

\section{Conceptual Foundation and Hypotheses}

As stated earlier, product-centric CIs after the start of production of a new product and its release in the market is a continuation of the innovation process, typically involving experimentation, learning, and creation of new knowledge or combining new with old knowledge (Almeida et al., 2003; Carlile and Rebentisch, 2003). As
Edmondson and Nembhard (2009, p. 124) point out, "Organizations that learn, that continuously improve their processes, products and services in ways that reflect changes in the external context, are likely to survive and thrive in an ever changing marketplace." More generally, organizational learning is the process of improving action as a reflection on new knowledge and understanding, and it is a critical source of competitive advantage (Argyris and Schon, 1978; Coutu, 2003; Fiol and Lyles, 1985; Garvin, 1993). This study draws on two phenomena related to organizational learning, namely the quality learning curve (Levin, 2000; Schneiderman, 1988; Sterman et al., 1997) and the manufacturing learning curve (Alchian, 1959; Levy, 1965; Wright, 1936), for understanding the impact of product-centric CIs on competitive capabilities and business performance.

\section{Types of Product-Centric CI Actions}

Extant literature has identified several reasons for making product-centric CIs, including: response to customer or vendor requests, design improvement of the equipment, revision of a unit or part to achieve economy, simplified tooling, ease of assembly, updating a special item to concur with present condition of its parent line, error condition at a time of original issue, new technology and process simplification, derivative products to exploit new marketing niches, modifications to match competitor innovation, safety- or defect-related modification, technological innovations of competitors, demand for customization, ease of manufacture, and cost reduction (Adler and Clark, 1991; Andrew, 1975; Balakrishnan and Chakravarty, 1996; Diprima, 1982; Hayes and Clark, 1985a, 1985b; Reidelbach, 1991). Balakrishnan and Chakravarty (1996) point out that the product-centric CIs are either initiated because of market-related considerations or because of manufacturing-related considerations. This point of view is consistent with Clark's (1996) concept of "performance frontier" and performance trade-offs that firms have to make when they are on the frontier. That is, typically, at the time of release of a new product into the market, the quality and cost attributes of the product have been optimized by a firm, implying that the product is on the "performance frontier" between quality and cost. Because, in this study, the product-centric CIs we are investigating are initiated to modify product design after the start of production of a new product and its release into the market, a firm faces a performance trade-off between cost reduction and quality improvement for initiating an action related to product-centric CI. Hence, the dominant drivers of 
product-centric $\mathrm{CI}$ actions are either quality improvement or cost reduction. In light of the above arguments, the following hypothesis is posited:

H1: The product-centric CI actions can be categorized based on whether they are actions for quality improvement or cost reduction.

The paragraphs to follow contain a discussion on how these two different categories of product-centric CI actions are associated with competitive capabilities related to quality and cost, and business performance.

\section{Impact of Product-Centric CI Actions for Quality Improvement}

Product-centric CI actions for quality improvement exploit the knowledge gained about technology and market after the start of production and commercial release of a product, leading to improved product quality and a product that matches better with the market needs. The relationship between the product-centric CIs and quality over the life cycle of a product is represented by a quality learning curve (Levin, 2000). The shape of quality improvement over the product life cycle takes the form of a learning curve in that after the easiest gains in quality have been made, new gains in quality come more slowly (Cole, 1990). Feedback to solve problems of quality is a function of time. First, root causes of quality problems are identified. Solutions are then proposed, designed, tested, and implemented until the problems are corrected. The effort then shifts on the next important source of problems. Learning in the quality domain occurs not only by the number of products manufactured, but also from the intensity of off-line activities. Increased experience leads to improved product quality, but in decreasing increments (Schneiderman, 1988; Sterman et al., 1997).

Although product-centric CIs can be initiated to improve product quality or to customize a product to meet a specific customer's requirement, such productcentric CIs can have an adverse effect on cost. A stable manufacturing environment facilitates development of the cost capabilities, but frequent product-centric CI actions for quality improvement disrupt this stability. The systematic reduction of unit cost with production experience or cumulative volume was first reported by Wright (1936) and later observed in several industrial settings (Alchian, 1959). The learning curve phenomenon is often represented by a negative exponential function (Levy, 1965). An underlying assumption is that a stable process improves production efficiency. The need for a process to be stable as a prerequisite for process improvement has also been recognized in the literature on statistical process control and total quality management (Deming, 1982). In light of the above arguments, the following set of hypotheses is posited:

H2a: Product-centric CI actions for quality improvement are positively associated with the capability to compete on quality.

H2b: Product-centric CI actions for quality improvement are negatively associated with the capability to compete on cost.

\section{Impact of Product-Centric CI Actions for Cost Reduction}

Now consider the impact for product-centric CI actions for cost reduction. Product-centric CI actions for cost reduction can disrupt the development of the technological capability essential for competing on quality. Frequent disruptions to quality improvement efforts can impede diffusion of newly acquired technical and market knowledge into the next generation of products. They can be a diversion from following the improvement trajectory predicted by a quality learning curve and disrupt the development of capabilities essential for competing on quality.

On the other hand, we expect firms initiating productcentric CI actions for cost reduction to use their knowledge of the product and process technology to move to a steeper learning curve and increase their cost capability. Cost reductions can come from elimination of existing features, application of lower cost technology or cheaper material, or making changes to product that are easier to manufacture. Experience provides a better understanding of the production processes. This experiential learning is similar to learning by doing (Pisano, 1994). The frequency with which product-centric CIs are initiated can be an indicator of the level of learning effort and technological capability essential for optimizing the product design to improve process efficiency. Therefore, we expect that product-centric $\mathrm{CI}$ actions for cost reduction will do just that-i.e., reduce costs. In light of the above arguments, the following set of hypotheses is posited:

H3a: Product-centric CI actions for cost reduction are negatively associated with the capability to compete on quality.

H3b: Product-centric CI actions for cost reduction are positively associated with the capability to compete on cost. 


\section{Impact on Business Performance}

Finally, we examine the effects of quality and cost capabilities on business performance. We infer from our review of the literature that there is an acknowledgement of the role of new product development in both developing and applying technological capability to gain competitive advantage (Cooper, 2003; Mohrman, Finegold, and Mohrman, 2003). We also infer from our review of the literature that product-centric CIs present opportunities to enhance and exploit technological capability for value creation even after a product has been released to the market. A product's perceived value is the customer's overall assessment of the utility of a product based on perceptions of what is received and what is given (Zeithaml, 1988). Therefore, the concept of value can be defined by the quality of the products customers receive for the price that they have to pay in exchange. Here we use "quality" to encompass both design quality (performance, features, durability, and reliability) as well as conformance quality that refers to how well products meet design specifications (Garvin, 1988). Hence, competitive advantage in the marketplace can be gained either by offering products with better quality, offering products at a lower price, or offering a combination of quality and price that is superior to competition. A firm's ability to lower price is limited below by its production cost (Lewis and Boyer, 2002). Therefore, we posit that competitive advantage can be gained through development of capabilities that will either improve a firm's ability to offer higher quality products or lower cost products or both. In light of the above arguments, the following set of hypotheses is posited:

H4a: The capability to compete on quality is positively associated with business performance.

H4b: The capability to compete on cost is positively associated with business performance.

Figure 1 integrates and depicts the proposed hypotheses in the form of a two-stage conceptual model.

\section{Research Design}

Following is a description of the data collection effort and the measures that are used to empirically test the hypotheses.

\section{Data Collection}

The database used for this study was developed for a larger study on manufacturing practices within the United

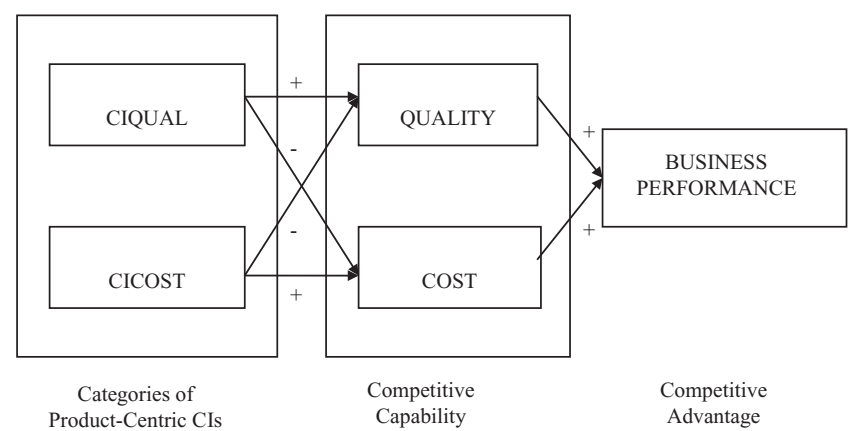

Figure 1. Hypothesized Relationships in the Conceptual Model

States. The survey instrument contained 170 questionnaire items organized in nine groups related to the primary product line and the dominant process at the plant level. The instrument was pilot tested with a small sample of typical respondents, and several questions were modified based on their feedback. A total of 400 questionnaires then were mailed, in two stages, to the plant managers in Midwest and Northeast regions of the United States selected from the Harris Industrial and Manufacturing Directory. Through telephone contacts, 200 plants were requested to participate in the study. A total of 110 of these plants returned their completed surveys. Subsequently, in order to increase the sample size, 200 additional questionnaires were mailed without any prior telephone contact. This mailing resulted in 34 additional completed surveys. In total, 144 completed questionnaires were returned for a response rate of $36 \%$.

Respondents' titles include president, vice president of manufacturing, vice president of operations, director of manufacturing, director of operations, plant manager, production manager, manufacturing manager, controllers, and strategic planning managers. The sample contained single-plant corporations, part of a division in a multidivision corporation, or part of multiplant corporations. The average asset value, annual sales, and number of employees were \$103 million, \$84 million, and 450 employees, respectively. Plants in the survey represented 15 industries at the two-digit standard industrial classification (SIC) code (20-39) level. Statistical comparisons of nonrespondents with respondents did not show any differences with respect to the size or industry. The distribution of plants across industries closely matched the distribution in the United States with two exceptions. Industrial and equipment plants were overrepresented, while petroleum and refining plants were underrepresented.

Because many of the variables in the survey were perceptual measures, there is a need to assess 
measurement errors. This assessment was achieved by creating a shorter version of the questionnaire (reduced to key 67 questionnaire items from the original survey instrument) and then sending it to a sample of the original plants. The shorter version clearly indicated the plant and the primary product line selected by the first respondent. The degree of agreement between the respondents was measured with interrater reliability scores (James, Demaree, and Wolf, 1984). The average interrater agreement was .77, indicating a satisfactory level of agreement between different respondents on the same product produced at the same plant. Moreover, for both objective and perceptual measures, we did not notice any statistically significant difference between the responses provided by two different informants.

\section{Measurement}

The unit of analysis for this study is the primary product line within an individual plant. The Appendix lists the original survey question items used as variables for testing the hypotheses presented in this study. All items (except for items 24 and 25 which are measured on a 4-point ordinal scale) are measured on a 5-point Likert scale, with one as the lowest and five as the highest score. Past research indicates that "objective" measures are not necessarily more reliable than perceptual measures (Ward, McCreery, Ritzman, and Sharma, 1998), and it is usually correlated with the perceptual measure (Vickery, Droge, and Markland, 1997; Ward, Leong, and Boyer, 1994). Respondents were asked to answer all questions in relation to the primary product line at an individual plant to eliminate inconsistencies in the unit of analysis (Flynn, Sakakibara, Schroeder, Bates, and Flynn, 1990).

Because all items are self-reported by a single respondent, we test for common method bias using Harman's one-factor test (Podsakoff and Organ, 1986) as recommended in the literature (e.g., Edmondson and Nembhard, 2009). All items were entered into a single exploratory factor analysis to determine whether a single factor would account for the majority of the covariance in the measures. No single dominant factor emerged, suggesting that common method bias is not a significant problem in the data (Podsakoff and Organ, 1986). Also, note that the highest pairwise correlation among the variables in our conceptual model is .49 (see Table 2). This value is below the threshold of .8 suggested by Bagozzi, Yi, and Phillips (1991) to indicate the presence of common method bias. Taken together, these results indicate that common method bias is not a consequential issue in this study.
Questionnaire items 1-8 state eight possible actions related to product-centric CIs as reported in the literature (see the Appendix on how the measured variables were phrased). To test the first hypothesis, principal component analysis on these eight items using varimax rotation to explore the underlying factor structure as recommended in the literature was performed (Carmines and Zeller, 1979). Only two factors with eigenvalues greater than one are retained. Notice that each item loads uniquely onto only one factor, i.e., each item has a factor loading higher than the minimum recommended .4 on a single factor only, and no item has a factor loading higher than .4 on both factors (Hair, Anderson, and Tatham, 1987). The two-factor solution is also confirmed by the scree plot of eigenvalues. Table 1 presents the rotated

Table 1. Constructs and the Relevant Items

\begin{tabular}{|c|c|c|}
\hline \multirow[b]{2}{*}{ Constructs and the Relevant Items } & \multicolumn{2}{|c|}{ Factor Loading } \\
\hline & Factor 1 & Factor 2 \\
\hline $\begin{array}{l}\text { Product-centric continuous improvement } \\
\text { actions }\end{array}$ & CIQUAL & CICOST \\
\hline $\begin{array}{l}\text { 1: Improve product performance due to new } \\
\text { technology }\end{array}$ & .62 & .36 \\
\hline $\begin{array}{l}\text { 2: Improve product performance with better } \\
\text { material }\end{array}$ & .63 & .37 \\
\hline 3: Eliminate design errors & .70 & -.14 \\
\hline 4: Add new features & .74 & -.04 \\
\hline 5: Reduce the number of features & .47 & .26 \\
\hline $\begin{array}{l}\text { 6: Reduce product cost due to new } \\
\text { technology }\end{array}$ & .05 & .78 \\
\hline 7: Reduce product cost with new material & .22 & .64 \\
\hline 8: Improve manufacturing efficiency & .00 & .82 \\
\hline $\begin{array}{l}\text { Reliability (Cronbach's } \alpha \text { for both CIQUAL } \\
\text { and CICOST) }\end{array}$ & 67 & .68 \\
\hline Competitive capability & QUALITY & COST \\
\hline 9: Product cost & .18 & .87 \\
\hline 10: Product performance & .80 & .31 \\
\hline 11: Number of features on the product & .58 & .19 \\
\hline 12: Product durability & .85 & .18 \\
\hline 13: Product reliability & .87 & .20 \\
\hline 14: Product quality consistency & .80 & .11 \\
\hline $\begin{array}{l}\text { 15: Product quality as perceived by the } \\
\text { customer }\end{array}$ & .66 & .23 \\
\hline 16: Product price & .26 & .82 \\
\hline $\begin{array}{l}\text { Reliability (Cronbach's } \alpha \text { for QUALITY; } \\
\text { Pearson correlation for COST) }\end{array}$ & .88 & $.52 * * *$ \\
\hline Business performance & BPERF & \\
\hline 17: Market share & .64 & \\
\hline 18: Sales growth & .85 & \\
\hline 19: Earning growth & .91 & \\
\hline 2: Profit margin & .81 & \\
\hline Reliability (Cronbach's $\alpha$ for BPERF) & .82 & \\
\hline
\end{tabular}


factor pattern. All questionnaire items on actions related to product-centric CIs are clearly separated into two categories: one related to improvement in product quality and the other related to reduction in production cost, thereby lending support to H1. Therefore, two separate constructs representing the two categories of productcentric CI actions were defined: one category to represent actions for quality improvement (CIQUAL) and the other category to represent actions for cost reduction (CICOST).

Questionnaire items 9-20 measure the position of the respondent's primary product line along several dimensions relative to the significant competition as used and validated in the previous literature (Mallick and Schroeder, 2005; Safizadeh, Ritzman, Sharma, and Wood, 1996). Principal component analysis of items 9-16 identified two unique factors (see Table 1). These two factors were used to develop measures for quality capability (QUALITY) and cost capability (COST). Principal component analysis on items 17-20 was also performed. All four items loaded on a single factor, which we use to measure the business performance (BPERF) of the primary product line (see Table 1). Following the literature, the term capability is used to define actual or realized competitive strength relative to the primary competition, which is different from the competitive priorities or desired capability (Boyer and Lewis, 2002). Similarly, business performance is defined by actual or realized competitive position of the primary product line relative to the primary competition.

As shown in Table 1, all the constructs discussed above have factor loading greater than the minimum recommended of .4 , and none of them cross load on more than one factor (Hair et al., 1987). All constructs, except for the two new ones introduced for this study, have reliability coefficients higher than the recommended minimum of .7, and the correlations are greater than the recommended minimum of .5 (Carmines and Zeller, 1979). The reliability estimates for the two new constructs (e.g., CIQUAL and CICOST) are close to .7, which is acceptable for new constructs (Flynn et al., 1990) or in exploratory research (Boyer and Pagell, 2000).

The measure for each multiple item scale (e.g., CIQUAL, CICOST, QUALITY, COST, and BPERFs) is constructed by taking the simple arithmetic average of all items representing that construct.

\section{Control Variables}

Besides product-centric CIs, there are other internal and external factors that have the potential to impact competi- tive capabilities and business performance. Hence, in testing the proposed $\mathrm{H} 2-4$, we control for six additional variables that are identified as important and relevant in the literature: industry structure (Porter, 1985), environmental dynamism (Akgun et al., 2007; Eisenhardt and Tabrizi, 1995), product characteristics (Hayes and Wheelwright, 1979; Kotha and Orne, 1989), process characteristics (Safizadeh, Ritzman, and Mallick, 2000), and scale of operations (Kotha and Orne, 1989).

Questionnaire items 21-25 measure these control variables. These items ask the respondents to characterize their external and internal environments along several dimensions. We use these items to measure environmental dynamism (DYNAMIC), product characteristics (CUSTOM), process characteristics (PCHOICE), and scale (VOLUME). We control for the industry effect by grouping the respondents into two dominant manufacturing sectors (Woodward, 1965), i.e., INDUSTRY $=0$ for process industry (e.g., SIC code $=20,24,26,28$, and 29) and INDUSTRY $=1$ for discrete manufacturing industry $($ SIC code $=30,32,33,34,35,36,37,38$, and 39). We measure DYNAMIC with the average of questions 21 and 22 (Spearman correlation of .53, $p<1 \%$ ), CUSTOM corresponds to item 23, PCHOICE corresponds to item 24, and VOLUME corresponds to item 25.

\section{Results}

The following is a discussion on the empirical analysis and results corresponding to the testing of H2-4.

\section{Analysis}

The summary descriptive statistics and Pearson correlations are presented in Table 2. While some correlations are not statistically significant, all significant correlations have signs that are consistent with the hypothesized relationships in the proposed conceptual model. Note that the signs for the correlations with COST construct are reversed because a higher value for the COST construct represents lower cost capability.

Because a two-stage conceptual model (Figure 1) that includes both direct and indirect paths is proposed, either a set of ordinary least squares (OLS) regression equations or path analysis could be used for estimating the model. A set of OLS regression equations is used because this method imposes less restrictive assumptions on the data and can be used with a smaller sample size compared with the path analysis (Shah and Goldstein, 2006). Similar approaches for small sample studies have been reported in the literature (e.g., Flynn and Saladin, 2001; Hausman, Montgomery, and Roth, 2002). 
Table 2. Descriptive Statistics and Pearson Correlations

\begin{tabular}{|c|c|c|c|c|c|c|c|c|c|c|c|c|}
\hline & $n$ & Mean & $\begin{array}{l}\text { Standard } \\
\text { Deviation }\end{array}$ & BPERF & QUALITY & COST & CIQUAL & CICOST & INDUSTRY & DYNAMIC & CUSTOM & PCHOICE \\
\hline BPERF & 91 & 3.41 & .82 & & & & & & & & & \\
\hline QUALITY & 91 & 3.70 & .64 & $.39 * * *$ & & & & & & & & \\
\hline COST & 91 & 3.36 & .65 & .17 & $.49 * * *$ & & & & & & & \\
\hline CIQUAL & 91 & 2.40 & .53 & .00 & $.21 * *$ & $.22 * *$ & & & & & & \\
\hline CICOST & 91 & 2.84 & .69 & .06 & -.11 & $-.18 *$ & $.30 * * *$ & & & & & \\
\hline INDUSTRY & 91 & .84 & .37 & .05 & .15 & $.22 * *$ & $.28 * * *$ & $.22 * *$ & & & & \\
\hline DYNAMIC & 91 & 3.61 & .65 & $.25 * *$ & .09 & .01 & .03 & .03 & $.21 * *$ & & & \\
\hline CUSTOM & 91 & 3.19 & 1.31 & -.06 & .00 & .04 & $.24 * *$ & .07 & $.34 * * *$ & .04 & & \\
\hline PCHOICE & 91 & 2.37 & 1.04 & .16 & $-.20 * *$ & $-.24 * *$ & $-.26 * *$ & -.10 & -.10 & .16 & $-.47 * * *$ & \\
\hline VOLUME & 91 & 2.65 & 1.13 & $.40 * * *$ & -.03 & -.11 & -.13 & .12 & -.03 & $.20 *$ & $-.20 *$ & $.51 * * *$ \\
\hline
\end{tabular}

$* * * p<.01 ; * * p<.05 ; * p<.1$.

BPERF, business performance; CICOST, cost reduction; CIQUAL, quality improvement; COST, cost capability; CUSTOM, product characteristics; DYNAMIC, environmental dynamism; INDUSTRY, industry type; PCHOICE, process characteristics; QUALITY, quality capability; VOLUME, scale.

The following set of three OLS regression models was used in two stages to represent the hypothesized relationships between the various constructs.

$$
\begin{aligned}
\text { QUALITY }= & \mathrm{a}_{1}+\mathrm{b}_{1} * \text { CIQUAL }+\mathrm{c}_{1} * \text { CICOST } \\
& +\mathrm{d}_{1} * \text { INDUSTRY }+\mathrm{e}_{1} * \text { DYNAMIC } \\
& +\mathrm{f}_{1} * \text { CUSTOM }+\mathrm{g}_{1} * \text { PCHOICE } \\
& +\mathrm{h}_{1} * \text { VOLUME }+\varepsilon_{1} \\
\text { COST }= & \mathrm{a}_{2}+\mathrm{b}_{2} * \text { CIQUAL }+\mathrm{c}_{2} * \text { CICOST } \\
& +\mathrm{d}_{2} * \text { INDUSTRY }+\mathrm{e}_{2} * \text { DYNAMIC } \\
& +\mathrm{f}_{2} * \text { CUSTOM }+\mathrm{g}_{2} * \text { PCHOICE } \\
& +\mathrm{h}_{2} * \text { VOLUME }+\varepsilon_{2}
\end{aligned}
$$

$$
\begin{aligned}
\text { BPERF }= & \mathrm{a}_{3}+\mathrm{b}_{3} * \text { QUALITY }+\mathrm{c}_{3} * \text { COST } \\
& +\mathrm{d}_{3} * \text { INDUSTRY }+\mathrm{e}_{3} * \text { DYNAMIC } \\
& +\mathrm{f}_{3} * \text { CUSTOM }+\mathrm{g}_{3} * \text { PCHOICE } \\
& +\mathrm{h}_{3} * \text { VOLUME }+\varepsilon_{3}
\end{aligned}
$$

\begin{tabular}{|c|c|c|c|c|c|c|}
\hline Dependent Variable (Y) & $\begin{array}{l}\text { Model 1a } \\
\text { QUALITY }\end{array}$ & $\begin{array}{c}\text { Model 2a } \\
\text { COST }\end{array}$ & $\begin{array}{c}\text { Model 3a } \\
\text { BPERF }\end{array}$ & $\begin{array}{l}\text { Model 1b } \\
\text { QUALITY }\end{array}$ & $\begin{array}{c}\text { Model 2b } \\
\text { COST }\end{array}$ & $\begin{array}{c}\text { Model 3b } \\
\text { BPERF }\end{array}$ \\
\hline Intercept & $4.01 * * *$ & $3.80 * * *$ & $2.27 * * *$ & $4.04 * * *$ & $4.02 * * *$ & .03 \\
\hline QUALITY & & & & & & $.52 * * *$ \\
\hline COST & & & & & & .04 \\
\hline CIQUAL & & & & $.27 * *$ & $.28 * *$ & \\
\hline CICOST & & & & $-.24 * *$ & $-.32 * * *$ & \\
\hline INDUSTRY & .31 & $.46^{* *}$ & .13 & .31 & $.50 * * *$ & -.05 \\
\hline DYNAMIC & .02 & -.02 & .12 & .01 & -.02 & .11 \\
\hline CUSTOM & -.09 & -.10 & -.02 & $-.11 *$ & $-.12 * *$ & .02 \\
\hline PCHOICE & $-.20 * *$ & $-.20 * *$ & -.05 & $-.21 * *$ & $-.22 * * *$ & .07 \\
\hline VOLUME & .06 & .02 & $.30 * * *$ & .09 & .06 & $.27 * * *$ \\
\hline $\mathrm{N}$ & 91 & 91 & 91 & 91 & 91 & 91 \\
\hline$F$ & 1.68 & $2.47 * *$ & $3.54 * * *$ & $2.34 * *$ & $3.71 * * *$ & $5.91 * * *$ \\
\hline$R^{2}$ & .09 & .13 & .17 & .17 & .24 & .33 \\
\hline Adjusted $R^{2}$ & .04 & .08 & .12 & .10 & .17 & .28 \\
\hline
\end{tabular}

Each one of the three relationships in the proposed model was tested independently, using the general linear model routine of the Statistical Analysis System (SAS, Version 9.2, SAS Institute, Cary, NC) package. The main results of the analysis are presented in Table 3.

Control variables. In stage one (Models 1a, 2a, and 3a in Table 3), the analysis of all three linear models is limited to the five control variables (i.e., INDUSTRY,

Table 3. Model Estimation Results

$* * * p<.01 ; * * p<.05 ; * p<.1$.

BPERF, business performance; CICOST, cost reduction; CIQUAL, quality improvement; COST, cost capability; CUSTOM, product characteristics; DYNAMIC, environmental dynamism; INDUSTRY, industry type; PCHOICE, process characteristics; QUALITY, quality capability; VOLUME, scale. 
DYNAMIC, CUSTOM, PCHOICE, and VOLUME). The regression Model 1a is not statistically significant. Model $2 \mathrm{a}$ is statistically significant, where $8 \%$ of the variance in COST is explained by the model, and only the two control variables, INDUSTRY and PCHOICE, are statistically significant. Finally, Model $3 \mathrm{a}$ is statistically significant, where $12 \%$ of the variance in BPERF is explained by the model, and only the control variable, VOLUME, is statistically significant.

In stage two (Models 1b, 2b, and 3b), the independent variables are introduced to test all of the remaining hypotheses.

$H 2 a$ and H3a. Model $1 \mathrm{~b}$ provides insight on the impact of the two categories of product-centric CI actionsnamely (1) actions for cost reduction and (2) actions for quality improvement-on QUALITY. Model $1 \mathrm{~b}$ is statistically significant and explains $10 \%$ of variance in QUALITY. We observe that CIQUAL is positively related with QUALITY $(p<.05)$ and CICOST is negatively related to QUALITY $(p<.05)$ as posited in H2a and $\mathrm{H} 3 \mathrm{a}$, respectively. Both control variables, CUSTOM and PCHOICE, are statistically significant in this model.

$H 2 b$ and $H 3 b$. Model $2 \mathrm{~b}$ serves to understand the impact of the two categories of product-centric CI actions on COST. Model $1 \mathrm{~b}$ is statistically significant and explains $17 \%$ variance in COST. Recalling the reverse sign of the COST construct, we observe that CIQUAL is negatively related with $\operatorname{COST}(p<.05)$ and positively related to CICOST $(p<.01)$. Thus, we have support for both $\mathrm{H} 2 \mathrm{~b}$ and $\mathrm{H} 3 \mathrm{~b}$. Both CUSTOM and PCHOICE are significant in this model.

$H 4 a$ and H4b. Regression Model $3 b$ tests the hypotheses where the relationships with business performance (BPERF) are posited. This model is statistically significant, where $28 \%$ of variance in BPERF is explained. There is strong support for $\mathrm{H} 4 \mathrm{a}$ because the regression coefficient of .52 is quite large and statistically significant $(p<.01)$. On the other hand, $\mathrm{H} 4 \mathrm{~b}$ is not supported because the regression coefficient for COST is not significant. VOLUME is the only significant control variable in this model.

In summary, there is empirical support for all hypothesized relationships except H4b. The empirically supported hypothesized relationships are pictorially depicted in Figure 2.

\section{Discussion}

Beginning with quality capability (QUALITY), Model $1 \mathrm{~b}$ suggests that the capability to compete on product

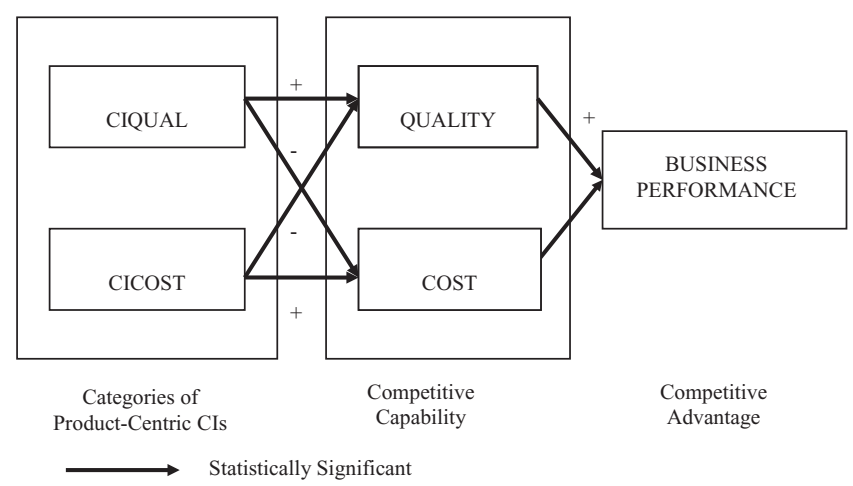

Figure 2. Observed Relationships in the Conceptual Model

quality is positively associated with CIQUAL but is negatively associated with CICOST. Approximately 6\% $\left(\Delta R^{2}=10 \%-4 \%\right)$ of the variance in a firm's quality capability is explained by these two categories of product-centric CIs. Through product-centric CI actions for quality improvement, firms exploit their knowledge of the technology and market following the quality learning curve to improve quality capability. With product-centric CI actions for cost reduction, on the other hand, firms may decide against improving product quality for cost containment or even take cost-cutting measures that may lead to reduction in product quality. The managerial implication of this result is that firms interested in building their quality capability should initiate product-centric CI actions for quality improvement while avoiding product-centric CI actions for cost reduction.

Now consider the cost capability (COST). Model 2b suggests that the capability to compete on cost is positively associated with CICOST but is negatively associated with CIQUAL. A significant portion $\left(\Delta R^{2}=17 \%-8 \%=9 \%\right)$ of the variance in Model $2 \mathrm{~b}$ is explained by the two categories of product-centric CI actions. Actions for cost reduction (CICOST) are significantly associated with the development of cost capability. Firms leverage their knowledge of technology and market to improve production efficiency, which moves its learning curve to a lower cost trajectory. However, a focus on cost alone without considering quality can reduce its ability to compete on quality. Also, improvement in conformance quality, which refers to conformance to design specifications only, can lead to cost reduction (Abernathy, Clark, and Kantrow, 1981; Crosby, 1979; Garvin, 1993). However, in this study, we are using a comprehensive view of quality that includes several other dimensions of quality such as performance, features, reliability, durability, and perceived quality that defines the inherent worth of a product (Garvin, 1988). Improvement in any of these 
other dimensions, often known as the design quality, is expected to increase costs (Juran, 1978; Roth, Cattani, and Froehle, 2008; Safizadeh et al., 2000). The managerial implication of these results is that while firms interested in building cost capability should be encouraging those product-centric CI actions that are intended to improve cost, they also need to be aware of their negative impact on quality.

Taken together, the statistical results for estimating Models $1 \mathrm{~b}$ and $2 \mathrm{~b}$ provide interesting insight into the relationship between the two categories of productcentric CI actions (i.e., CIQUAL and CICOST) and the two dimensions of capabilities (i.e., QUALITY and COST). The results indicate presence of a trade-off for either category of CI actions. While there is positive association between both categories of CI actions, e.g., CIQUAL is positively associated with QUALITY and CICOST is positively associated with COST, there is also a negative association between one type of CI action on the other type of capability dimension, e.g., CIQUAL is negatively associated with COST, CICOST is negatively associated with QUALITY. A possible theoretical explanation of this trade-off is the simultaneous presence of both quality learning curve and manufacturing learning curve phenomenon as identified in the literature (e.g., Levin, 2000; Levy, 1965). That is, CIQUAL facilitates improvement along the quality learning curve but disrupts the manufacturing learning curve, whereas CICOST facilitates improvement along the manufacturing learning curve but disrupts the quality learning curve. The practical implication of this finding is that once managers are aware of the presence of the trade-off discussed above, they will be in a position to make better decisions regarding when to initiate what type of CI actions and at the same time minimize the negative influence of the actions.

Finally, consider the overall business performance (BPERF). Although business performance is affected by many controllable and uncontrollable factors (we control for five such factors for which data is available), Models $3 \mathrm{a}$ and $3 \mathrm{~b}$ show that a significant portion of the variance explained $\left(\Delta R^{2}=28 \%-12 \%=16 \%\right)$ with respect to a firm's business performance is affected by QUALITY. Overall business performance is positively affected by the capability to create value through better quality product as is posited in $\mathrm{H} 4 \mathrm{a}$, but not from a lower cost product as is posited in $\mathrm{H} 4 \mathrm{~b}$.

There are several possible explanations for this counterintuitive result on COST. One possible explanation is that both measured variables (items 9 and 16) going into the COST construct were worded so that higher values mean lower cost capability. This wording might have confused some of the respondents. However, it seems unlikely that many respondents misread both questions. Another explanation is that gains in quality capability outweigh the losses in cost capability. In order to test for this alternative explanation, a separate regression model with specification like Model 3b, except that QUALITY was excluded as an independent variable, was estimated. This revised model was statistically significant, including the relationship between the COST and BPERF constructs. Perhaps the effect of cost capability on business performance is partialed out by the effect of quality capability. Even though on surface $\mathrm{H} 4 \mathrm{~b}$ was not statistically supported, the result is hidden in Models 3a and $3 \mathrm{~b}$. This finding is interesting because (1) a large proportion of all product-centric CIs are aimed at cost reduction and (2) a significant part of the literature on managing product-centric CIs is focused on cost minimization.

Actually, these findings on COST are in congruence with the contradictory impact of product-centric CI actions on productivity improvement reported in the literature (Adler and Clark, 1991; Hayes and Clark, 1985a, 1985b; Moorman and Miner, 1998). However, this could be the result of aggregating two different categories of product-centric CIs. By explicitly recognizing the two separate categories of product-centric CIs, this study provides a more insightful explanation of the phenomenon reported in the literature (cf. Adler and Clark, 1991).

\section{Conclusion}

Product-centric CIs represent significant opportunities for gaining and sustaining competitive advantage through product design modifications throughout the life cycle of a product. Yet, the literature has predominantly viewed product-centric CIs as a disruption and a challenge rather than as an opportunity. The lack of understanding of how product-centric CIs affect the competitive capabilities and business performance has hindered product-centric CIs being initiated strategically (Wright, 1998). And, to that end, we conducted an empirical investigation using survey data from 144 plants in the United States (belonging to process and discrete manufacturing industries) where we explicitly recognized two categories of product-centric CI actions: (1) actions for quality improvement and (2) actions for cost reduction.

The empirical analysis results of this study indicate strong linkages between quality capability and business performance. However, the linkage between cost capability and business performance needs to be further investi- 
gated. The results indicate that product-centric CIs have a significant impact on competitive capabilities and, hence, on business performance. Therefore, product-centric CIs can be managed to develop competitive capabilities and improve business performance. The results also suggest that there can be trade-offs between quality and cost capabilities. Finally, because the two categories of product-centric $\mathrm{CI}$ actions that were identified are actions for cost reduction and actions for quality improvement, insights from this paper have the potential to enable managers to better understand the basis for initiating the two categories of product-centric CIs, their impact on developing competitive capabilities, and, in turn, on business performance.

Like any study, this study, too, has limitations. One limitation arises from the fact that it was not possible to account for all possible actions related to product-centric CIs in this paper. And the analysis was restricted to product-centric $\mathrm{CIs}$ that were included in the original survey instrument (Appendix), the implication of which could be lower reliability for the two new constructs used for the measuring product-centric CI categories. Although these levels of reliability scores are considered acceptable for new constructs (Flynn et al., 1990) and in exploratory research (Boyer and Pagell, 2000), caution needs to be exercised to not treat the findings of this study as being definitive. Instead, the results should be viewed as an illustration of the relationships posited in the proposed hypotheses, depicted pictorially in Figure 1. Further corroboration of the hypothesized relationships would be a logical direction for future research. The second limitation of the study stems from the wording of the questionnaire items used for cost and price that may have confused some respondents. Unlike other questionnaire items measuring competitive capabilities, higher scores on items related to cost and price implies lower performance. However, price and cost are well defined in the literature. Hence, it is doubtful that very many respondents were confused with both measured variables. Items 9 and 20 have a Spearman correlation coefficient of .52 $(p<.01)$, indicating a very acceptable level of reliability for the COST construct. At any rate, the measured variables for future research should avoid this possible confusion.

The final limitation is that we used frequency of product-centric CIs as a measure of engineering effort. An underlying assumption is that engineering effort related to product-centric CIs are of equal magnitude. Some product-centric CIs require more engineering effort or are more disruptive than others, yet these differences were not recognized in this study. However, this assump- tion should not affect the conceptual model or the empirical results because of the monotonic nature of the proposed hypotheses. This approach complements studies that have used engineering hours as a measure of engineering effort (Adler and Clark, 1991). Future research should explore the combined effect of the frequency and magnitude of product-centric CIs.

In closing, this paper-instead of focusing on the disruptive effects and downside risks of product-centric CIs, a perspective that dominates the extant literature-sheds light on the upside potential of product-centric CI actions by categorizing them into actions for cost reduction and quality improvement, respectively, and demonstrating the impact of the two categories of product-centric CIs on a firm's competitive capabilities and business performance. We hope that the findings of this study will motivate both scholars and practitioners to further pursue this promising line of inquiry.

\section{References}

Abernathy, W. J., K. B. Clark, and A. M. Kantrow. 1981. The new industrial competition. Harvard Business Review 59 (5): 68-81.

Adler, P. S., and K. B. Clark. 1991. Behind the learning curve: A sketch of the learning process. Management Science 37 (3): 267-81.

Akgun, A. E., J. C. Byrne, G. S. Lynn, and H. Keskin. 2007. New product development in turbulent environments: Impact of improvisation and unlearning on new product performance. Journal of Engineering and Technology Management 24 (3): 203-30.

Alchian, A. A. 1959. Costs and output. In The allocation of economic resources: Essays in honor of B. F. Halev, ed. M. Abramowitz, 23-40. Stanford, CA: Stanford University Press.

Almeida, P., A. Phene, and R. Grant. 2003. Innovation and knowledge management: Scanning, sourcing, and integration. In The Blackwell handbook of organizational learning and knowledge management, ed. M. Easterby-Smith and M. A. Lyles, 356-71. Malden, MA: Blackwell Publishing.

Andrew, C. G. 1975. Engineering changes to the product structure opportunity for MRP users. Production and Inventory Management 16 (3): 76-86.

Argyris, C., and D. A. Schon. 1978. Organizational learning: A theory of action perspective. Reading, MA: Addison-Wesley.

Bagozzi, R. P., Y. Yi, and L. W. Phillips. 1991. Assessing construct validity in organizational research. Administrative Science Quarterly 36 (3): 421-58.

Balakrishnan, N., and A. K. Chakravarty. 1996. Managing engineering change: Market opportunities and manufacturing costs. Production and Operations Management 5 (4): 335-56.

Barzizza, R., M. Caridi, and R. Cigolini. 2001. Engineering change: A theoretical assessment and a case study. Production Planning \& Control 12 (7): 717-26.

Bohn, R. E., and C. Terwiesch. 1999. The economics of yield-driven processes. Journal of Operations Management 18 (1): 41-59.

Boyer, K. K., and M. W. Lewis. 2002. Competitive priorities: Investigating the need for trade-offs in operations strategy. Journal of Operations Management 11 (1): 9-20.

Boyer, K. K., and M. Pagell. 2000. Measurement issues in empirical research: Improving measures of operations strategy and advanced manufacturing technology. Journal of Operations Management 18 (3): $361-74$. 
Carlile, P. R., and E. S. Rebentisch. 2003. Into the black box: The knowledge transformation cycle. Management Science 49 (9): 1180-95.

Carmines, E. G., and R. A. Zeller. 1979. Reliability and validity assessment. Thousands Oak, CA: Sage Publications.

Chalmet, L. G., M. De Bodt, and L. Van Wassenhove. 1985. The effect of engineering changes and demand uncertainty on MRP lot sizing: A case study. International Journal of Production Research 23 (2): 233-51.

Chen, Y.-M., W.-S. Shir, and C.-Y. Shen. 2002. Distributed engineering change management for allied concurrent engineering. International Journal of Computer Integrated Manufacturing 15 (2): 127-51.

Clark, K. B. 1996. Competing through manufacturing and the new manufacturing paradigm: Is manufacturing strategy passé? Production and Operations Management 5 (1): 42-58.

Cole, R. 1990. US quality improvement in the auto industry: Close but no cigar. California Management Review 32 (4): 71-85.

Cooper, L. P. 2003. A research agenda to reduce risk in new product development through knowledge management: A practitioner perspective. Journal of Engineering and Technology Management 20 (1, 2): $117-40$.

Coutu, D. L. 2003. Sense and reliability: A conversation with celebrated psychologist Karl E. Weick. Harvard Business Review 81 (4): 84-90.

Crosby, P. B. 1979. Quality is free. New York, NY: McGraw-Hill.

Deming, W. E. 1982. Out of the crisis. Cambridge, MA: MIT Press.

Diprima, M. 1982. Engineering change control and implementation considerations. Production and Inventory Management 23 (1): 81-87.

Edmondson, A. C., and I. M. Nembhard. 2009. Product development and learning in project teams: The challenges are the benefits. Journal of Product Innovation Management 26 (2): 123-38.

Eisenhardt, K. M., and B. N. Tabrizi. 1995. Accelerating adaptive processes: Product innovation in the global computer industry. Administrative Science Quarterly 40 (1): 84-110.

Fiol, C. M., and M. A. Lyles. 1985. Organizational learning. Academy of Management Review 10 (4): 803-13.

Flynn, B. B., S. Sakakibara, R. G. Schroeder, K. A. Bates, and E. J. Flynn. 1990. Empirical research methods in operations management. Journal of Operations Management 9 (2): 250-73.

Flynn, B. B., and B. Saladin. 2001. Further evidence on the validity of the theoretical models underlying the Baldrige criteria. Journal of Operations Management 19 (19): 617-53.

Garvin, D. A. 1988. Managing quality: The strategic and competitive edge. New York: Free Press.

Garvin, D. A. 1993. Building a learning organization. Harvard Business Review 71 (4): 78-91.

Hair, J. F., R. E. Anderson, and R. L. Tatham. 1987. Multivariate data analysis. Upper Saddle River, NJ: Prentice-Hall.

Hausman, W. H., D. B. Montgomery, and A. V. Roth. 2002. Why should marketing and manufacturing work together? Some exploratory empirical results. Journal of Operations Management 20 (3): 241-59.

Hayes, R. H., and K. B. Clark. 1985a. Exploring the sources of productivity difference at the factory level. In The uneasy alliance, ed. K. B. Clark, R. H. Hayes, and C. Lorenz, 151-88. Boston, MA: Harvard Business School Press.

Hayes, R. H., and K. B. Clark. 1985b. Explaining observed productivity differentials between plants: Implications for operations research Interfaces 15 (6): 3-14.

Hayes, R. H., and S. C. Wheelwright. 1979. Link manufacturing process and product life cycles. Harvard Business Review 57 (1): 133-40.

Ho, C. J. 1994. Evaluating the impact of frequent engineering changes on MRP system performance. International Journal of Production Research 32 (3): 619-41.

Huang, G. Q., and K. L. Mak. 1999. Current practices of managing engineering changes in U.K. manufacturing industries. International Journal of Operations \& Production Management 19 (1): 21-37.
Huang, G. Q., W. Y. Yee, and K. L. Mak. 2001. Development of a webbased system for engineering change management. Robotics and Computer Integrated Manufacturing 17: 255-67.

James, L. R., R. G. Demaree, and G. Wolf. 1984. Estimating within-group interrater reliability with and without response bias. Journal of Applied Psychology 69 (1): 85-98.

Juran, J. M. 1978. Japanese and western quality: A contrast. Quality Progress 11 (12): 10-18.

Kotha, S., and D. Orne. 1989. Generic manufacturing strategy: A conceptual synthesis. Strategic Management Journal 10 (3): 211-31.

Leonard-Barton, D. 1996. Wellsprings of knowledge: Building and sustaining sources of innovation. Boston, MA: Harvard Business School Press.

Levin, D. Z. 2000. Organizational learning and the transfer of knowledge: An investigation of quality improvement. Organization Science 11 (6): 630-47.

Levy, F. K. 1965. Adaptation in the production process. Management Science 11 (6): B136-B154.

Lewis, M. W., and K. K. Boyer. 2002. Factors affecting AMT implementation: An integrative and controlled study. Journal of Engineering and Technology Management 19 (2): 111-30.

Loch, C. H., and C. Terwiesch. 1999. Accelerating the process of engineering change orders: Capacity and congestion effects. Journal of Product Innovation Management 16 (2): 145-59.

Mallick, D. N., and R. G. Schroeder. 2005. An integrated framework for measuring new product development performance in high-technology industry. Production and Operations Management 14 (2): 142-48.

Mather, H. 1977. Reschedule the reschedules you just rescheduled: Way of life for MRP? Production and Inventory Management Journal 18 (4): 60-79.

Mohrman, S. A., D. Finegold, and A. M. Mohrman, Jr. 2003. An empirical model of the organization knowledge system in new product development firms. Journal of Engineering and Technology Management 20 $(1,2): 7-38$.

Moorman, C., and A. S. Miner. 1998. The convergence of planning and execution: Improvisation in new product development. Journal of Marketing 62 (3): 1-20.

Pikosz, P., and J. Malmqvist. 1998. A comparative study of engineering change management in three Swedish engineering companies. Proceedings of 1998 ASME Design Engineering Technical Conference, September, Atlanta, GA, 13-6.

Pisano, G. P. 1994. Knowledge, integration and the locus of learning: An empirical analysis of process development. Strategic Management Journal 15 (S1): 85-100.

Podsakoff, P. M., and D. W. Organ. 1986. Self-reports in organizational research: Problems and prospects. Journal of Management 12 (4): 531-44.

Porter, M. E. 1985. Competitive advantage: Creating and sustaining superior performance. New York: Free Press.

Reidelbach, M. A. 1991. Engineering change management for long-leadtime production environments. Production and Inventory Management Journal 32 (2): 84-88.

Roth, A. V., K. D. Cattani, and C. M. Froehle. 2008. Antecedents and performance outcomes of global competence: An empirical investigation. Journal of Engineering and Technology Management 25 (1, 2): 75-92.

Saeed, B. I., D. M. Bowen, and V. S. Sohoni. 1993. Avoiding engineering changes through focused manufacturing knowledge. IEEE Transactions on Engineering Management 40 (1): 54-59.

Safizadeh, M. H., L. P. Ritzman, and D. N. Mallick. 2000. Revisiting alternative theoretical paradigms in manufacturing strategy. Production and Operations Management 9 (2): 111-27.

Safizadeh, M. H., L. P. Ritzman, D. Sharma, and C. Wood. 1996. An empirical analysis of the product-process matrix. Management Science 42 (11): 1576-91. 
Schmenner, R., and C. Lackey. 1994. Slash and burn doesn't kill weeds: Other ways to downsize the manufacturing organization. Business Horizons 37 (4): 80-87.

Schneiderman, A. M. 1988. Setting quality goals. Quality Progress 21 (4): $51-57$.

Shah, R., and S. M. Goldstein. 2006. Use of structural equation modeling in operations management research: Looking back and forward. Journal of Operations Management 24 (2): 148-69.

Soderberg, L. G., K. P. Coyne, and R. W. Ferguson Jr. 1989. Facing up to the engineering gap. The McKinsey Quarterly 89 (1): 3-23.

Sterman, J. D., N. P. Repenning, and F. Kofman. 1997. Unanticipated side effects of successful quality programs: Exploring a paradox of organizational improvement. Management Science 43 (4): 503-21.

Tavcar, J., and J. Duhovnik. 2005. Engineering change management in individual and production. Robotics and Computer-Integrated Manufacturing 21 (3): 205-15.

Terwiesch, C., and R. E. Bohn. 2000. Learning and process improvement during production ramp-up. International Journal of Production Economics 70 (1): 1-19.

Terwiesch, C., and C. H. Loch. 1999. Managing the process of engineering change orders: The case of the climate control system in automobile development. Journal of Product Innovation Management 16 (2): 16072.

Thomke, S. H. 1998. Simulation, learning and R\&D performance: Evidence from automotive development. Research Policy 27 (1): 55-74.

Vickery, S. K., C. Droge, and R. E. Markland. 1997. Dimensions of manufacturing strength in the furniture industry. Journal of Operations Management 15 (4): 315-30.
Wanstorm, C., and P. Johnson. 2006. The impact of engineering changes on materials planning. Journal of Manufacturing Technology Management 17 (5): 561-84.

Wanstorm, C., F. Lind, and O. Wintertidth. 2006. Creating a model to facilitate the allocation of materials planning resources in engineering change situations. International Journal of Production Research 44 (18-19): 3775-96.

Ward, P. T., G. K. Leong, and K. K. Boyer. 1994. Manufacturing proactiveness and performance. Decision Sciences 25 (3): 337-58.

Ward, P. T., J. K. McCreery, L. P. Ritzman, and D. Sharma. 1998. Competitive priorities in operations management. Decision Sciences 29 (4): 1035-46.

Watts, F. 1984. Engineering changes: A case study. Production and Inventory Management Fourth Quarter: 55-62.

Wheelwright, S. C., and K. B. Clark. 1992. Creating project plans to focus product development. Harvard Business Review 70 (2): 70-82.

Woodward, J. 1965. Industrial organization: Theory and practice. London, UK: Oxford University Press.

Wright, I. C. 1998. A review of research in the engineering change management: Implications for product design. Design Studies 18 (1): $33-42$.

Wright, T. P. 1936. Factors affecting the cost of airplanes. Journal of Aeronautical Science 3 (February): 122-28.

Zeithaml, V. A. 1988. Consumer perceptions of price, quality, and value: A means-end model and synthesis of evidence. Journal of Marketing 52 (3): 2-22.

\section{Appendix. Original Questionnaire Items Used for Analysis}

\section{Product-Centric Continuous Improvement Actions}

Please indicate the amount of changes made annually in the products in your primary product line due to the reasons listed below (check one box for each item):

No Changes Few Changes Some Changes Many Changes Very Many Changes

1. Improve product performance due to new technology

2. Improve product performance with better material

3. Eliminate design errors

4. Add new features

5. Reduce the number of features

6. Reduce product cost due to new technology

7. Reduce product cost with cheaper material

8. Improve manufacturing efficiency (reduce processing time or setup time; or improve quality)

$\begin{array}{lllll}- & - & - & - & - \\ - & - & - & - & - \\ - & - & - & - & - \\ - & - & - & - & - \\ - & - & - & - & - \\ - & - & - & - & - \\ - & - & - & - & - \\ - & - & - & - & (5) \\ (1) & (2) & (3) & (4) & \end{array}$




\section{Competitive Capabilities}

Relative to your significant competitors, please indicate your position on the following dimensions (check one box for each item):

\begin{tabular}{lccccc}
\hline & $\begin{array}{c}\text { Significantly } \\
\text { Lower }\end{array}$ & $\begin{array}{c}\text { Somewhat } \\
\text { Lower }\end{array}$ & $\begin{array}{c}\text { About the } \\
\text { Same }\end{array}$ & $\begin{array}{c}\text { Somewhat } \\
\text { Higher }\end{array}$ & $\begin{array}{c}\text { Significantly } \\
\text { Higher }\end{array}$ \\
\hline 9. Product cost & - & - & - & - & - \\
10. Product performance & - & - & - & - & - \\
11. Number of features on product & - & - & - & - & - \\
12. Product durability & - & - & - & - & - \\
13. Product reliability & - & - & - & - & - \\
14. Product quality consistency & - & - & - & - & - \\
15. Product quality as perceived by customer & - & - & - & - & $(5)$ \\
16. Product price & $(1)$ & $(2)$ & $(3)$ & & \\
\end{tabular}

\section{Business Performance}

Relative to your significant competitors, please indicate your position on the following dimensions (check one box for each item):

\begin{tabular}{lccccc}
\hline & Significantly Lower & Somewhat Lower & About the Same & Somewhat Higher & Significantly Higher \\
\hline 17. Market share & - & - & - & - & - \\
18. Sales growth & - & - & - & - & - \\
19. Earning growth & - & - & - & - & - \\
20. Profit margin & - & $(2)$ & $(3)$ & - & $(4)$ \\
\end{tabular}

\section{Environmental Dynamism}

What has been the trend in your major industry (the industry in which your company compete with its primary product line) on the following items compared to three years ago?

\begin{tabular}{lccccc}
\hline & $\begin{array}{c}\text { Significantly } \\
\text { Decreased }\end{array}$ & $\begin{array}{c}\text { Somewhat } \\
\text { Decreased }\end{array}$ & $\begin{array}{c}\text { About the } \\
\text { Same }\end{array}$ & $\begin{array}{c}\text { Somewhat } \\
\text { Increased }\end{array}$ & $\begin{array}{c}\text { Significantly } \\
\text { Increased }\end{array}$ \\
\hline 21. Technological changes in product & - & - & - & - & - \\
22. Technological changes in process & - & - & - & - & - \\
& $(1)$ & $(2)$ & $(3)$ & $(4)$ & $(5)$ \\
\hline
\end{tabular}

\section{Scale of Operation}

23. How would you characterize the demand for your primary product line?

\begin{tabular}{lcccc}
\hline Low Volume & Moderate Volume & High Volume & Significantly High Volume & Very High Volume \\
\hline$(1)$ & $(2)$ & $(3)$ & (4) & (5) \\
\hline
\end{tabular}




\section{Product Characteristics}

24. Which of the following descriptions most typify the production in your plant?

$\begin{array}{lcccc}\begin{array}{l}\text { Standard product } \\ \text { with no options }\end{array} & \begin{array}{c}\text { Standard product with } \\ \text { standard options }\end{array} & \begin{array}{c}\text { Standard product modified } \\ \text { to customer specification }\end{array} & \begin{array}{c}\text { Standard product option modified } \\ \text { to customer specification }\end{array} & \begin{array}{c}\text { Customized product manufactured } \\ \text { to customer specification }\end{array}\end{array}$

\section{Process Characteristics}

25. Which of the following categories come closest to characterizing your dominant processes?

\begin{tabular}{lccc}
\hline Job Shop_ & Batch Shop_ & Production Line_ & Continuous Shop__ \\
\hline$(1)$ & $(2)$ & (3) & (4) \\
\hline
\end{tabular}

Job Shops: Products are produced in small batches; similar equipments performing the same functions are grouped together.

Batch Shops: Products are produced in moderately large batches; similar equipments performing the same functions are grouped together.

Production Line: Products are produced in small batches; work centers are laid out in the sequence in which the products are manufactured.

Continuous Shop: Products are produced in large batches or in a continuous flow; work centers are laid out in the sequence in which the products are manufactured. 